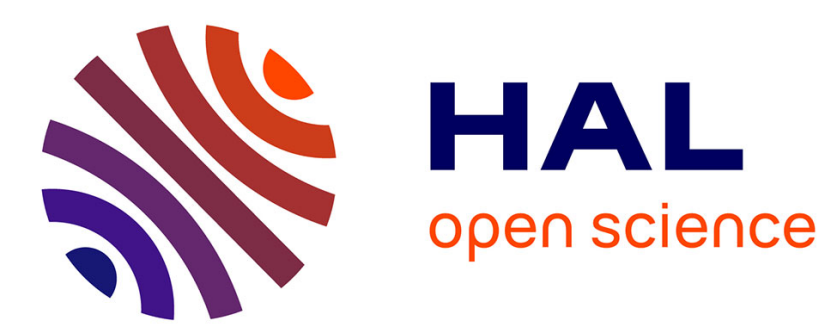

\title{
Experimental studies of Portevin-Le Chatelier plastic instabilities in carbon-manganese steels by infrared pyrometry
}

\author{
Nicolas Ranc, W Du, I Ranc, D Wagner
}

\section{To cite this version:}

Nicolas Ranc, W Du, I Ranc, D Wagner. Experimental studies of Portevin-Le Chatelier plastic instabilities in carbon-manganese steels by infrared pyrometry. Materials Science and Engineering: A, 2016, 663, pp.166-173. 10.1016/j.msea.2016.03.096 . hal-01377562

HAL Id: hal-01377562

https://hal.science/hal-01377562

Submitted on 7 Oct 2016

HAL is a multi-disciplinary open access archive for the deposit and dissemination of scientific research documents, whether they are published or not. The documents may come from teaching and research institutions in France or abroad, or from public or private research centers.
L'archive ouverte pluridisciplinaire HAL, est destinée au dépôt et à la diffusion de documents scientifiques de niveau recherche, publiés ou non, émanant des établissements d'enseignement et de recherche français ou étrangers, des laboratoires publics ou privés. 


\title{
Experimental studies of Portevin-Le Chatelier plastic instabilities in carbon-manganese steels by infrared pyrometry
}

\author{
N. Ranc ${ }^{\mathrm{a}, *, 1}$, W. Du ${ }^{\mathrm{b}}$, I. Ranc ${ }^{\mathrm{b}}$, D. Wagner ${ }^{\mathrm{b}}$ \\ a PIMM, UMR CNRS 8106, Arts et Métiers-ParisTech, 151 Boulevard de l'Hôpital, 75013 Paris, France \\ ${ }^{\mathrm{b}}$ Université Paris Ouest Nanterre, LEME, 50 rue de Sèvres, 92410 Ville d'Avray, France
}

\begin{abstract}
A B S T R A C T
The dynamic strain aging (DSA) phenomenon that occurs in some materials under certain temperature and strain rate conditions can cause plastic strain localization in the form of Portevin-Le Chatelier (PLC) bands. Carbon-manganese steels are used commonly and frequently in construction because of their ductility, low cost and ability to form mechanically. In these steels, the DSA phenomenon occurs for common quasi-static strain rates from 150 to $300^{\circ} \mathrm{C}$, which makes band observation complicated. PLC bands on a carbon-manganese steel that was sensitive to DSA were studied using an infrared camera. Specimen heating was achieved using an induction furnace (with an adapted coil inductor), which allows for temperature recording during tensile tests. Thermography with an infrared camera was used to estimate the band characteristics and increments in band plastic strain, which is an important parameter for material behavior identification necessary for DSA phenomenon modeling. This technique had been developed only for PLC phenomenon observation at ambient temperature on aluminum alloys. Band characteristics on the carbon-manganese steels have been compared with results obtained previously on aluminum alloys.
\end{abstract}

\section{Introduction}

Carbon-manganese (C-Mn) steels are common steels that are used frequently in construction because of their ductility, low cost and ability to form mechanically. The metallurgy of these steels is complex, because of the interaction of solute atoms with dislocations during deformation, which leads to metallurgical instabilities, which include Lüders strain, static strain aging (SSA) and dynamic strain aging (DSA). If these metallurgical instabilities induce an increase in hardness, they produce a decrease in ductility that is detrimental to component safety [1-10].

Lüders strain appears at the transition between elastic and plastic domains from 20 to $200{ }^{\circ} \mathrm{C}$. At the upper yield stress, the stress drops suddenly; plastic deformation begins at one side of the specimen and propagates as a plastic front through the length of the sample. SSA occurs if unloading is conducted during homogeneous plastic deformation, followed by heat treatment at $200{ }^{\circ} \mathrm{C}$ over a few minutes and reloading. This results in a return of the Lüders strain phenomenon. These phenomena (Lüders and SSA) are visible at room temperature. Thereafter, plastic deformation is homogeneous during the

\footnotetext{
* Corresponding author

E-mail address: nicolas.ranc@ensam.eu (N. Ranc).

1 http://pimm.paris.ensam.fr/fr/user/9.
}

test until area reduction occurs.

In DSA, aging is sufficiently rapid to occur during straining. Strain localization is characterized in a tensile test by the formation and propagation of plastic strain bands termed Portevin-Le Chatelier (PLC) bands. During tensile tests at an imposed strain rate, DSA is associated with serrations on the stress-strain curve $[4,11-16]$. Each stress drop on the tensile curve corresponds to the formation of a band. Three types of bands form: type A corresponds to the continuous propagation of a plastic front along the specimen, type $\mathrm{B}$ corresponds to a discontinuous but regular propagation of bands and type $C$ corresponds to chaotic formation along the specimen (discontinuous and uncorrelated). At a microscopic scale, this phenomenon is related to the interaction of mobile dislocations with the interstitial solute atoms. Dislocation gliding is discontinuous [17-21], and the dislocations are stopped temporarily on the obstacles (forest, precipitates) during a waiting time $t_{w}$. During this waiting time, solute atom diffusion creates additional anchoring of dislocations. This anchoring effect is active in a strain rate and temperature domain. In C-Mn steels, the DSA phenomenon occurs for common quasi-static strain rates for 150 $300{ }^{\circ} \mathrm{C}$, which complicates observations $[9,10]$.

In C-Mn steels, carbon and nitrogen atoms interact with dislocations. Because of its greater solubility limit, nitrogen seems to influence aging more than carbon does [1,5,22,23]. The location of these atoms is rather complex $[9,10]$. One part is precipitated as 
carbides $\left(\mathrm{Fe}_{3} \mathrm{C}\right)$ or nitrides $\left(\mathrm{Fe}_{4} \mathrm{~N}, \mathrm{Fe}_{16} \mathrm{~N}_{2}\right.$ or aluminum nitride if aluminum is present). The other part is in solid solution in the centered cubic iron lattice. The part in solid solution is distributed in three locations [24-26]. Most of the atoms gather and form "Cottrell atmospheres". Some segregate near dislocations in the interstitial sites and, when all sites near the dislocations are occupied, the remaining solute atoms are free in the lattice interstitial sites. It appears that solute atoms in "Cottrell atmospheres" cause SSA and thus the Lüders phenomenon. Moreover, it has been demonstrated that in C-Mn steels, free carbon and nitrogen in the interstitial sites are responsible for DSA [27]. Recently, literature models and C-Mn steels have been reviewed by [28,29].

PLC band observation on aluminum alloys has been studied extensively. In this case, DSA occurs at room temperature. The techniques used are optical extensometry [30-33], speckle interferometry [34-39], digital image correlation [40-44] or thermography with an infrared camera [45-48]. The advantage of this latter technique is that increments of plastic strain in the bands can be estimated. This is an important parameter that is useful for material behavior identification and is necessary for DSA phenomenon modeling. However, this technique has only been developed for the PLC phenomenon at ambient temperature.

In this study, infrared thermography has been used at $200{ }^{\circ} \mathrm{C}$, which is the operating temperature for DSA in C-Mn steels. Specimen heating was achieved using an induction furnace (with an adapted coil inductor), which allows for temperature recording during the tensile tests. After the study material has been presented, the experimental techniques are described and the experimental results (band characteristics) are presented and compared with aluminum alloy results in literature.

\section{Experimental setup}

\subsection{Material}

C-Mn was received as a $40-\mathrm{mm}$-thick plate. Its chemical composition (weight percent) is reported in Table 1 . The plate was treated by prior normalization thermal treatment, which included austenitizing at $900{ }^{\circ} \mathrm{C}$ followed by furnace cooling (to $300{ }^{\circ} \mathrm{C}$ ) and air cooling. This leads to a microstructure that is composed of banded ferrite and pearlite.

This material contains too little aluminum $(0.0085 \%)$ to allow for full precipitation of nitrogen atoms by aluminum nitride formation during cooling from the austenitic region. Consequently, after this heat treatment, some free nitrogen still exists in the lattice, which makes this alloy sensitive to DSA.

\subsection{Loading device and specimen}

Tensile tests were carried out using a hydraulic tensile machine. Grip displacement was controlled to obtain a constant velocity. Two grip velocities were considered. The nominal tensile strain was deduced from the measurement of grip displacements and the tensile stress was measured using a force sensor. Specimen geometry is given in Fig. 1. The specimen was placed at the center of the inductor of an induction furnace, and its temperature was controlled to ensure that it remained constant at the specimen center. Temperature control time was shorter than the required for PLC band formation.

Table 1

Composition of C-Mn steel.

\begin{tabular}{lllll}
\hline & $\mathrm{C}$ & $\mathrm{N}$ & $\mathrm{Mn}$ & $\mathrm{Al}$ \\
\hline Weight \% & 0.190 & 1.07 & 0.011 & 0.0085 \\
\hline
\end{tabular}

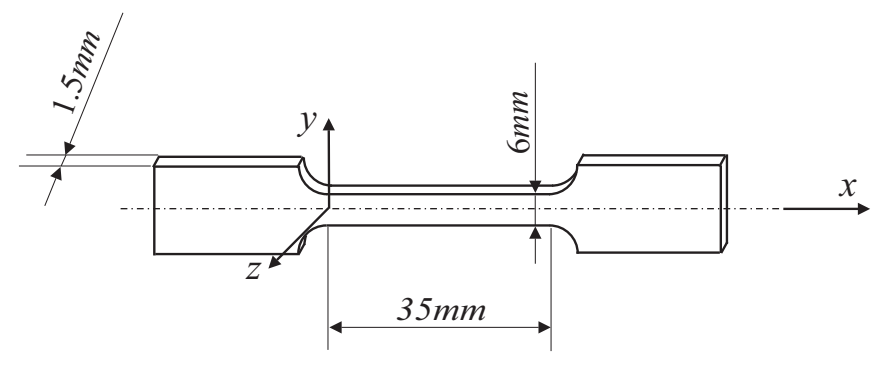

Fig. 1. Tensile test specimen geometry.

Table 2 lists the nominal strain rate and mean temperature for various tests.

\subsection{PLC band observation technique}

As mentioned previously, various techniques have been used to study PLC bands and to quantify their parameters (bandwidth, apparent propagation velocity, increase in plastic deformation in the band). We have used an infrared thermography measurement technique that was developed 10 years ago $[45,46]$. This technique has been used in many previous studies on PLC at ambient temperature [45-57]. One advantage of this technique is that it allows for the estimation of band parameters and for a following of their evolution during the entire tensile test. In this paper, infrared thermography has been adapted to the study of PLC phenomena at higher temperature and in particular, for the study of C-Mn steels.

The principle of this technique is based on a measure of the temperature field on the specimen surface induced by plastic energy dissipated in heat during band formation. The links between plastic strain in the band and the temperature field measured is given by a heat transfer equation. A homogeneous temperature can be assumed for flat specimens of small thickness, and the heat transfer equation is written as:

$\rho C \frac{\partial T}{\partial t}=\sigma: \dot{\varepsilon}_{p}+k\left(\frac{\partial^{2} T}{\partial x^{2}}+\frac{\partial^{2} T}{\partial y^{2}}\right)-\frac{2 h}{e}\left(T-T_{a m b}\right)$

where $\rho$ is the density, $C$ is the heat capacity per unit mass, $k$ is the thermal conductivity, $h$ is the convection coefficient, $e$ is the specimen thickness and $T_{a m b}$ is the ambient temperature. The first term on the right-hand side represents the heat source associated with dissipated plastic energy, where $\sigma$ and $\varepsilon$ are the stress and strain tensors, respectively. It is supposed here that the plastic energy is dissipated completely as heat. The second term represents heat transfer from heat conduction. This term is a priori not equal to zero as soon as the temperature field remains heterogeneous. The last term of Eq. (1) corresponds to thermal losses by convection and radiation on the specimen surface.

If losses are neglected, i.e., convection, radiation and conduction terms are neglected compared with thermal inertia, the heat equation can be simplified and is given after time integration:

$\rho C \Delta T=\sigma: \Delta \varepsilon_{p}$.

Under these conditions, a proportionality relation exists between the temperature variation $\Delta T$ and the increment in plastic strain $\Delta \varepsilon_{p}$. This adiabatic assumption is valid as soon as temperature increments are measured over short times. For example, this case exists when the variation in temperature as measured between two images taken by the camera and the frequencies of acquisition are sufficiently large. In this paper, this adiabatic assumption will always be made and associated errors from thermal losses on estimated parameters will be quantified.

An infrared charge-coupled device camera was used to measure temperature variation fields associated with the dissipation of 
Table 2

Test conditions.

\begin{tabular}{|c|c|c|c|c|}
\hline Testnumber & Nominalstrain rate & Meantemperature $\left({ }^{\circ} \mathrm{C}\right)$ & Aperturetime $(\mu \mathrm{s})$ & Samplingfrequency $(\mathrm{Hz})$ \\
\hline 1 & $10^{-2} s^{-1}$ & 200 & 50 & 150 \\
\hline 2 & $10^{-3} s^{-1}$ & 200 & 25 & 150 \\
\hline
\end{tabular}

plastic energy inside a PLC band. Its spectral sensitivity is in the near infrared domain between $3.9 \mu \mathrm{m}$ and $4.5 \mu \mathrm{m}$. Thermal radiation from the specimen surface was focused on the camera array with an objective and focal length of $50 \mathrm{~mm}$. The spatial resolution was $0.27 \mathrm{~mm}$. Aperture times of $25 \mu \mathrm{s}$ and $50 \mu$ s were used, which allows for coverage of a temperature range from $100{ }^{\circ} \mathrm{C}$ to $300{ }^{\circ} \mathrm{C}$. The sampling frequency of the camera is $150 \mathrm{~Hz}$, which corresponds to $7 \mathrm{~ms}$ between two temperature fields. The camera parameters for the two tests are reported in Table 2. The camera and the optical device were calibrated using an extended blackbody. Fig. 2 shows the calibration curves for two aperture times. For a blackbody temperature of $200^{\circ} \mathrm{C}$, fluctuations are $0.55{ }^{\circ} \mathrm{C}$ for aperture times of $25 \mu$ s and the detection limit of the system at this temperature is defined. These fluctuations induce lower signal to noise ratio than those obtained at ambient temperature [47].

To eliminate the effect of emissivity on temperature measurements, the specimen surface was covered with a thin layer of black mat paint, which can resist temperatures of up to $600{ }^{\circ} \mathrm{C}$.

\section{Experimental results}

Fig. 3 shows the temperature field at the beginning of test 1 . The temperature field is heterogeneous along the specimen axis because of thermal losses on the specimen edges. However, Fig. 3a shows that the temperature heterogeneity remains small $(\approx 10 \%)$ in a $10 \mathrm{~mm}$ domain at the specimen center.

Fig. 4 shows the stress according to the nominal strain for the two strain rate values. The nominal strain is deduced from a displacement of the specimen edge. The two stress strain curves exhibit serrations that are characteristic of PLC band occurrence. It is difficult to identify the type of PLC band from these curves. When the nominal strain rate increases, the yield stress decreases. This corresponds to a negative sensitivity to the strain rate, which is a consequence of the PLC phenomenon.

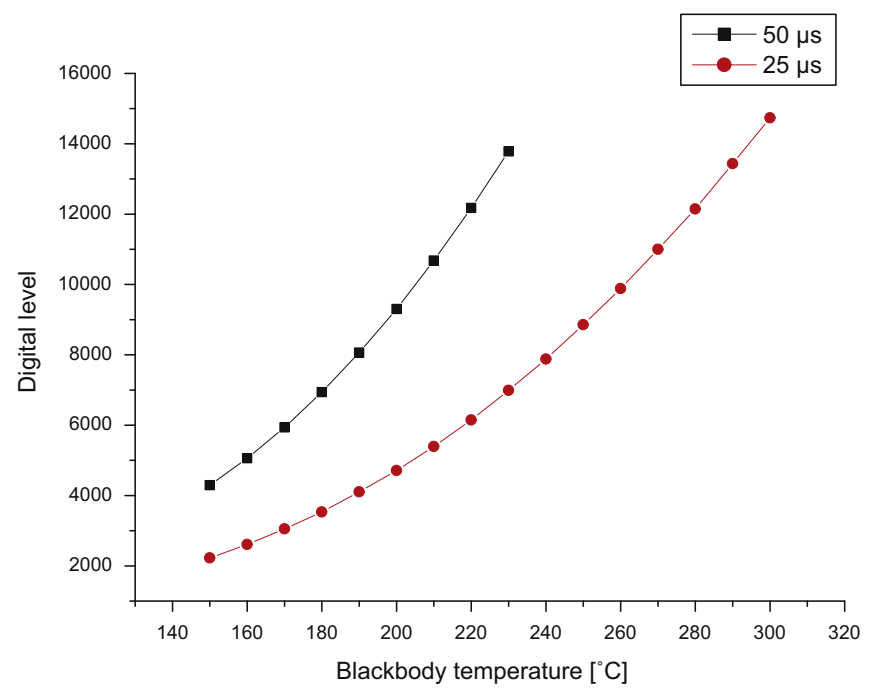

Fig. 2. Calibration curves of infrared camera.

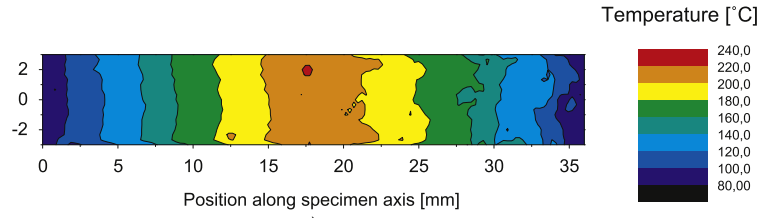

a)

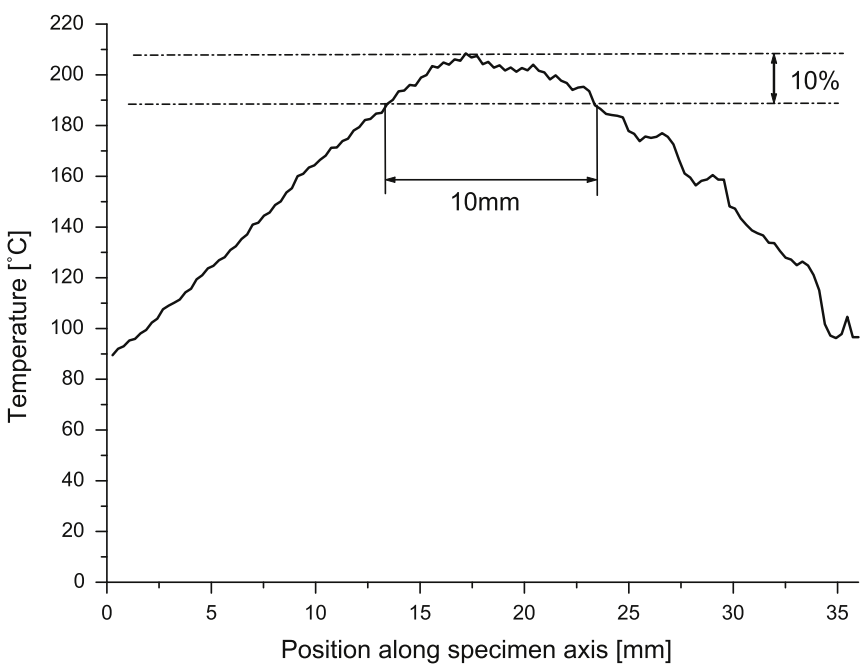

b)

Fig. 3. Initial temperature field.

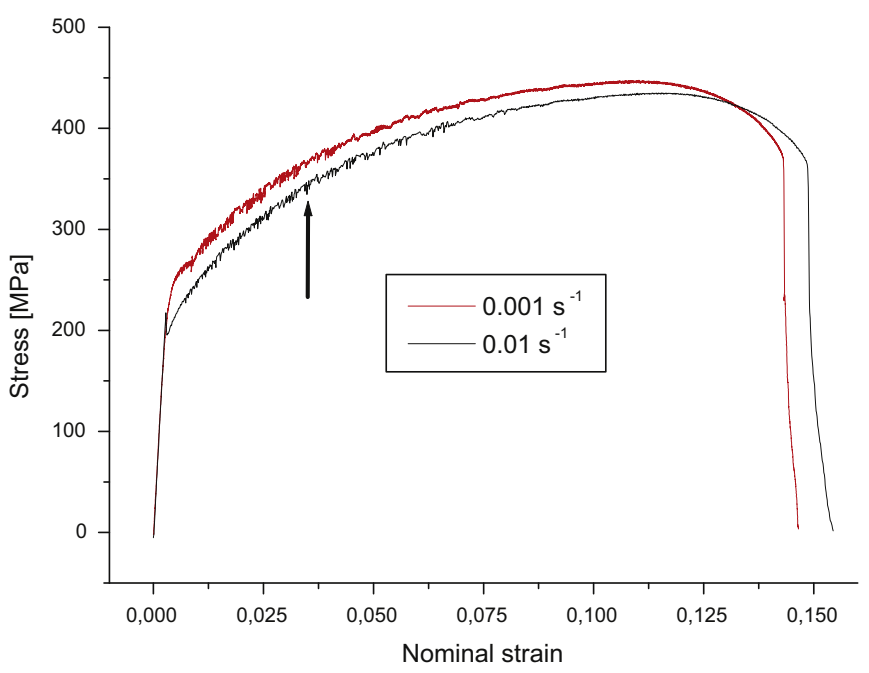

Fig. 4. Stress strain curves for the two tests.

First we focus on test 1 with a strain rate of $10^{-2} \mathrm{~s}^{-1}$. Fig. 5 shows the specimen surface temperature evolution at two points, which correspond to the location of two consecutive bands at a nominal strain of 0.035 and is located in the specimen center. The nominal strain is marked by an arrow on Fig. 4. The rapid increase in temperature for the two curves on Fig. 5 corresponds to band formation. The temperature increments during two consecutive 


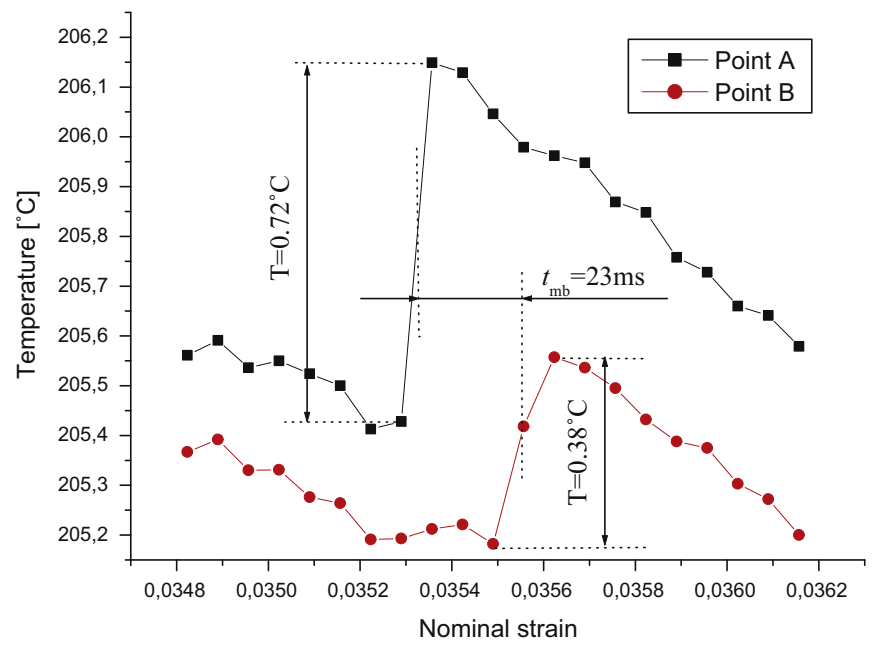

Fig. 5. Temperature evolution in the center of two consecutive bands (test 1 at a strain rate of $10^{-2} \mathrm{~s}^{-1}$ ).

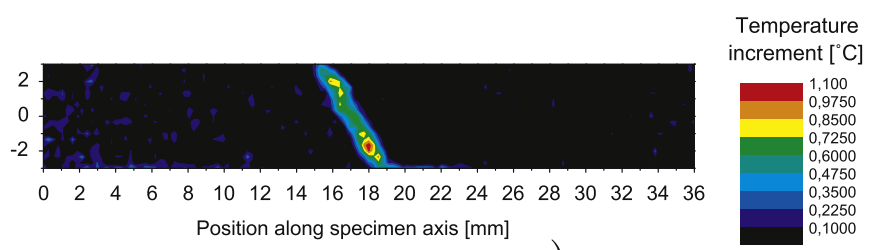

a)

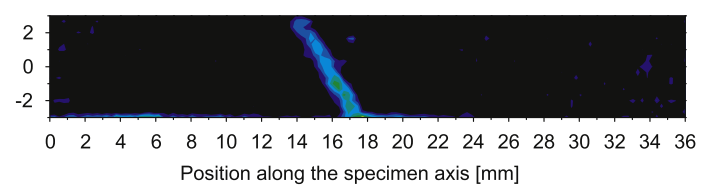

b)

Fig. 6. Temperature increase field during (a) first and (b) second band formations (test 1 at a strain rate of $10^{-2} \mathrm{~s}^{-1}$ ).

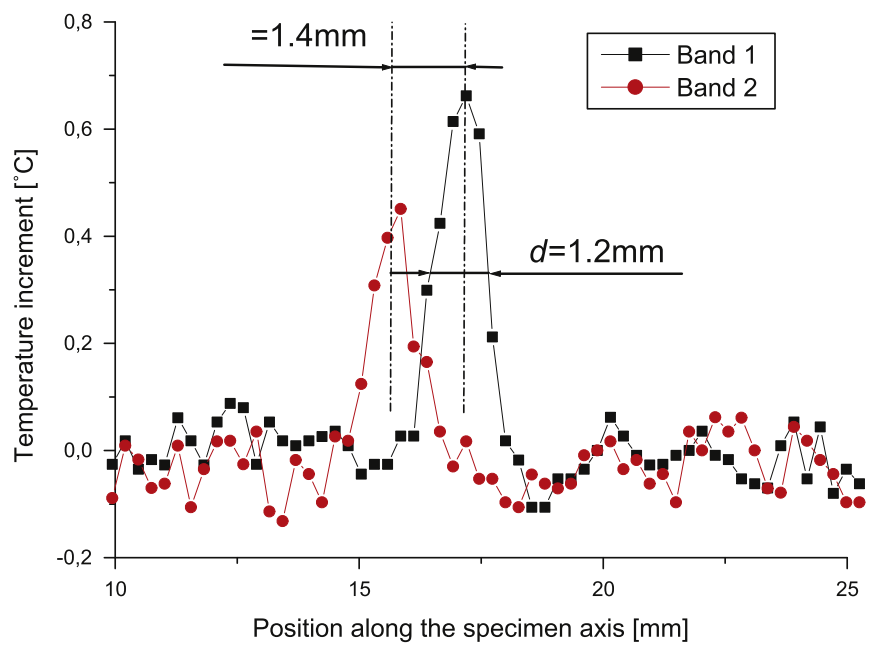

Fig. 7. Temperature increment along specimen axis for two consecutive bands (test 1 at a strain rate of $10^{-2} \mathrm{~s}^{-1}$ ).

bands are $0.72{ }^{\circ} \mathrm{C}$ and $0.38{ }^{\circ} \mathrm{C}$. A time of $23 \pm 3 \mathrm{~ms}$ is estimated between the two band formations. From these two curves, two temperature fields, before and after the band formation, can be established. These temperature fields are represented on Fig. 6. The band angle with specimen axis can also be measured and is $54 \pm 2^{\circ}$. To determine the bandwidth and distance between two consecutive bands, the evolution in incremental temperature along the specimen axis, $x$, is shown in Fig. 7. Fig. 7 allows the band width at middle height and the distance between the two bands to be defined. For two consecutive bands, the bandwidth and the distance between the two bands are equal to $1.2 \mathrm{~mm}$ and $1.4 \mathrm{~mm}$, respectively. The error in distance between two consecutive bands is equal to the pixel size, $0.27 \mathrm{~mm}$ in our case, and is unaffected by heat diffusion by conduction. For the bandwidth, heat conduction between band formation and the moment when the camera measures the temperature field tends to overestimate the bandwidth. An estimate of this error can be made by using a unidimensional heat diffusion model where the heat conduction and heat losses from convection with the surroundings are taken into account. This model is detailed and is solved in appendix Alloblackburneus for a bandwidth of $1.2 \mathrm{~mm}$ and an acquisition frequency of $150 \mathrm{~Hz}$, the maximum error on the estimated bandwidth is $0.18 \mathrm{~mm}$, which corresponds to $16 \%$.

The position of all detected bands can be represented according to the nominal strain rate. Fig. 8 shows the normalized position along the specimen axis for each band for test 1. Bands 1 and 2 are represented with a white box. Fig. 8 enables us to highlight the spatio-temporal organization of the PLC bands. Type C and B bands occur during these two tensile tests. The domain where the temperature can be considered as homogeneous and close to $200{ }^{\circ} \mathrm{C}$ is delimited by two dashed lines. Fig. 9 shows the same representation for test 2 at a nominal strain rate of $10^{-3} \mathrm{~s}^{-1}$.

These curves allow for the determination of time between two band formations and the distance between two consecutive bands to represent their evolution during the test. Figs. 10 and 11 represent evolutions in distance and time between two consecutive bands. For these two data sets, the full square represents bands being formed in the center of the specimen where the temperature is close to $200{ }^{\circ} \mathrm{C}$ with a margin of $10 \%$. Empty squares represent bands formed outside this zone. Fig. 10 shows that the distance between bands exhibits small variations compared with the space resolution during the test. For two nominal strain rates, this distance is $1.2 \mathrm{~mm}$, with an uncertainty of $0.27 \mathrm{~mm}$ related to the space resolution of the camera. The time between two band formations is more dispersed. This dispersion occurs from the heterogeneity in temperature along the specimen length, which can affect the band parameters significantly. If only the bands that occur in the central zone of the specimen where the temperature is close to $200{ }^{\circ} \mathrm{C}$ are taken into account, fewer dispersed curves are obtained. An increase in duration between two band

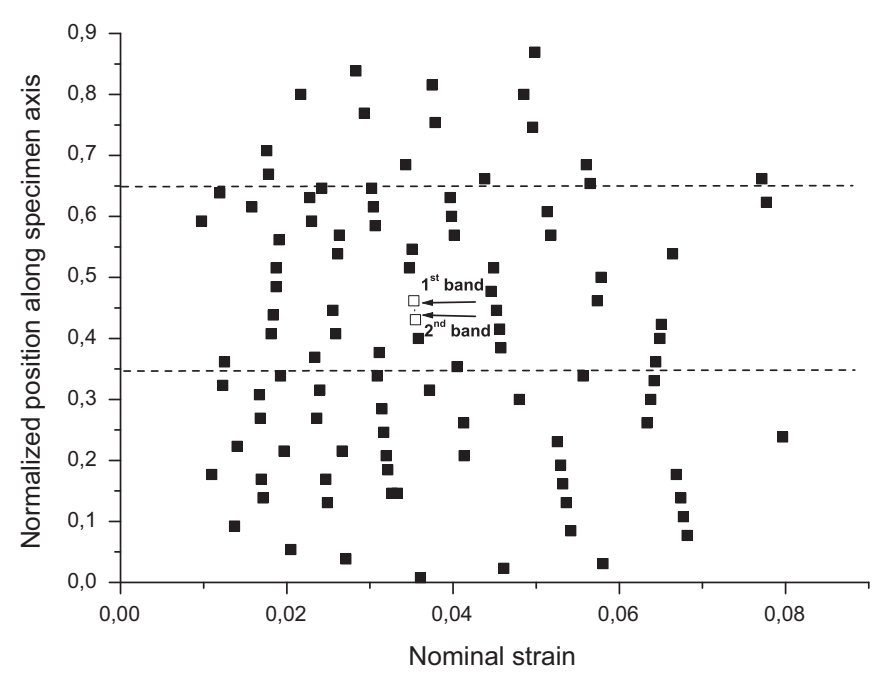

Fig. 8. Normalized position of bands along the specimen axis (test 1 at a strain rate of $\left.10^{-2} \mathrm{~s}^{-1}\right)$. 


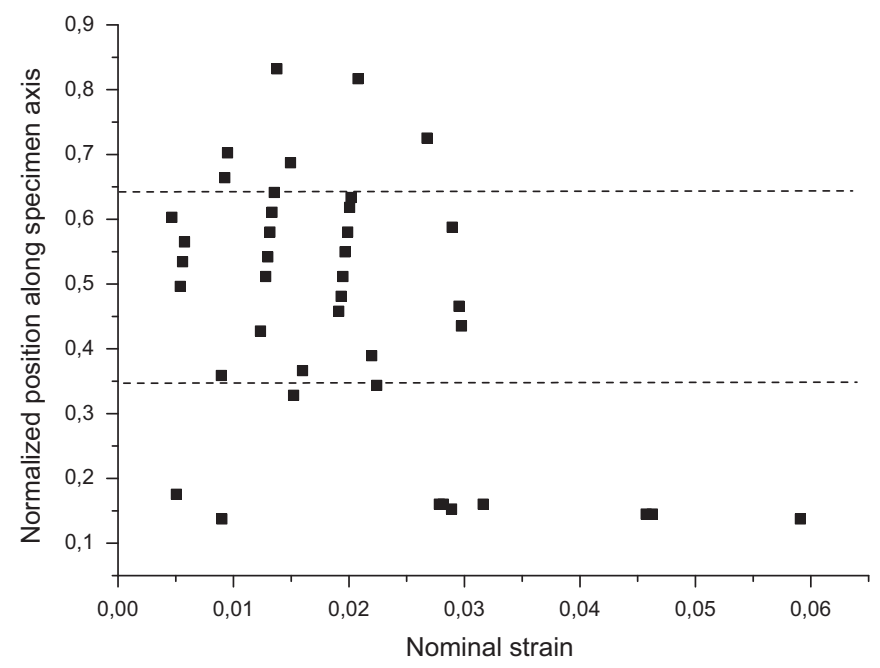

Fig. 9. Temperature increment along specimen axis for two consecutive bands (test 2 at a strain rate of $10^{-3} \mathrm{~s}^{-1}$ ).

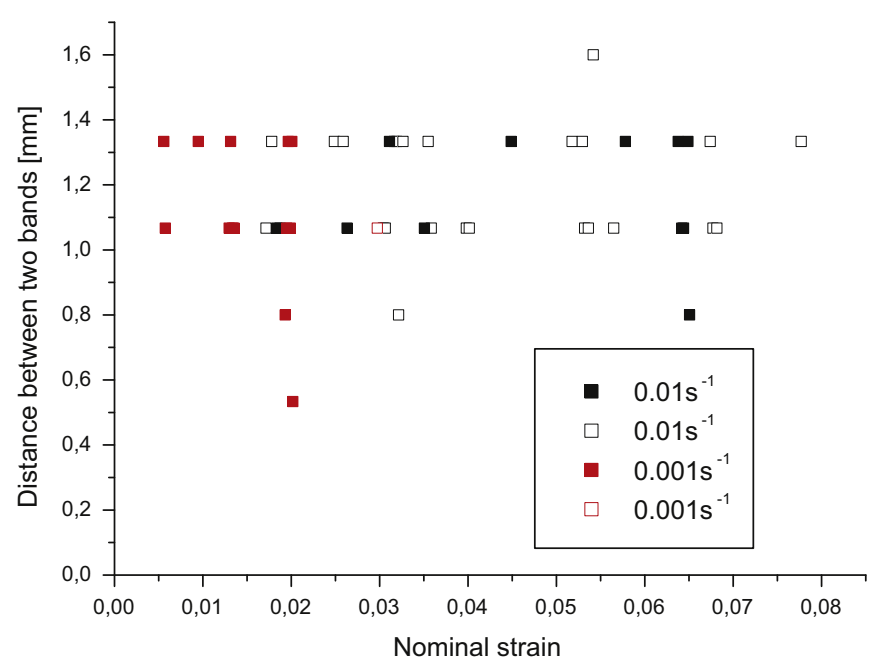

Fig. 10. Distance between two consecutive bands according to nominal strain.

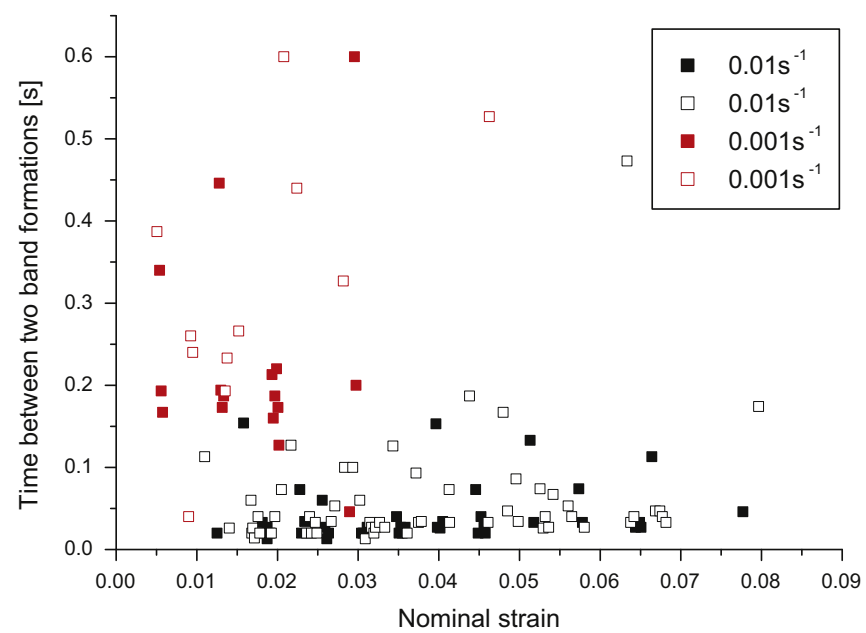

Fig. 11. Time between two consecutive bands according to nominal strain.

formations can be detected for test 1 . An increase in time between two band formations occurs when the nominal strain rate decreases. An explanation of this effect was given in [47]: Orowan's law expresses the dislocation waiting time $t_{w}$ according to the

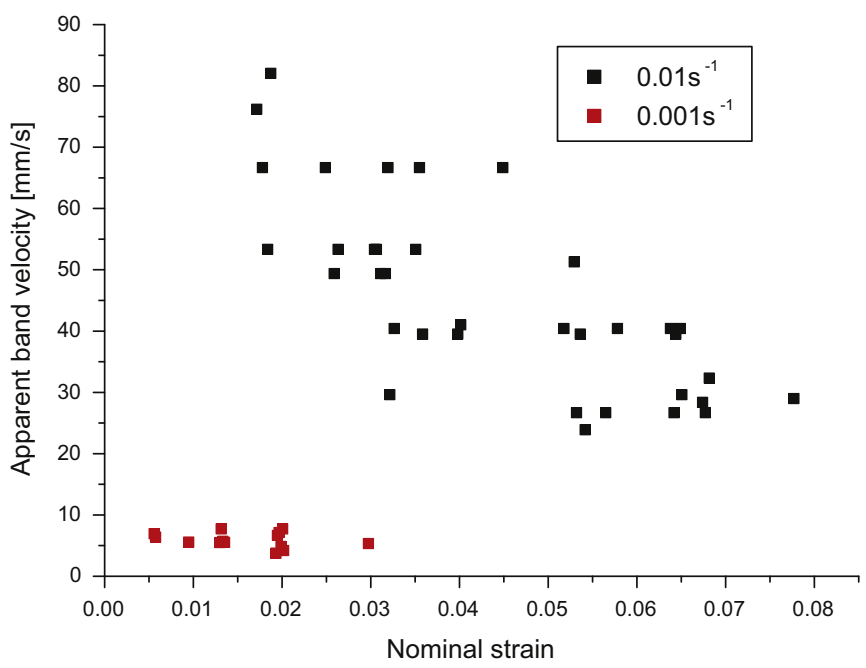

Fig. 12. Apparent band velocity according to nominal strain.

strain rate and the elementary plastic strain, $\Omega$, which corresponds to the strain obtained when all mobile dislocations accomplish a successful activation event:

$t_{w}=\frac{\Omega}{\dot{\varepsilon}}$

When the plastic strain increases, the elementary plastic strain increases because of dislocation multiplication [58]. Thus, the waiting time and the time between two band formations increases. When the strain rate increases, the waiting time and the time between two band formations decrease, as observed during the experiments.

From the time, $t_{m b}$, and distance, $\delta$, between two bands, an apparent propagation velocity for type $\mathrm{B}$ bands can be defined by:

$v_{a p p}=\frac{\delta}{t_{m b}}$

Fig. 12 represents an evolution of this apparent velocity and highlights that this apparent velocity decreases with nominal strain and increases with nominal strain rate.

For each band, the temperature increment can be represented according to nominal strain and for the two strain rates. Fig. 13 represents this evolution and shows that the results are dispersive. No effect of strain rate and nominal strain can be highlighted, and a mean value of increment of $0.3^{\circ} \mathrm{C}$ can be determined. The heat equation in the adiabatic case allows the plastic strain increment in the band to be deduced with the following equation:

$\Delta \varepsilon=\frac{\rho C \Delta T}{\sigma}$

For C-Mn steel, the density, heat capacity and axial stress for a nominal strain of $15.8 \%$ are equal to $7800 \mathrm{~kg} \mathrm{~m}^{-3}, 460 \mathrm{~J} \mathrm{~kg}^{-1} \mathrm{~K}^{-1}$ and $343 \mathrm{MPa}$, respectively, and a plastic strain increment of $0.3 \%$ can be calculated.

\section{Discussion}

The PLC effect has been studied extensively, especially for aluminum alloys. Measurements by thermography are very useful to quantify macroscopic characteristics of bands and to observe their evolution during tests and for various nominal strain rates. In this discussion, results obtained in the previous paragraphs for C-Mn steel will be compared with those for an $\mathrm{Al}-\mathrm{Cu}-\mathrm{Mg}$ alloy detailed in another publication [47]. 
C-Mn steel and aluminum alloys that contain copper and magnesium have different aging mechanisms. For the $\mathrm{AlCu}_{4} \mathrm{Mg}$ alloy studied by Ranc et al. [47], before loading, the materials undergo heating to $500{ }^{\circ} \mathrm{C}$ to achieve solution treatment of copper and magnesium in the aluminum alpha phase with cubic facecentered crystalline structure. This heat treatment enables us to concentrate these two elements in the aluminum crystal lattice. For C-Mn steel, carbon and nitrogen are inserted into the centered cubic iron lattice. The diffusion velocity of the solute atoms is very different in these two materials and is much slower in the aluminum alloy than in steel [59](page 67).

The PLC effect also depends on the material microstructure such as, for example, its grain size. C-Mn steel has an equiaxed grain microstructure and a slightly dispersed average ferrite grain size of 13$30 \mu \mathrm{m}$ with an average size of $19 \mu \mathrm{m}$. For aluminum alloy, grains are slightly lengthened and the grain size is less dispersed with an average of approximately $20 \mu \mathrm{m}$. The steel and aluminum alloy grain sizes are thus comparable. The PLC phenomenon and, more particularly, the band characteristics are also very dependent on specimen geometry and tensile testing machine characteristics such as its rigidity. In the two studies, "hard machines" with high rigidities were used. However, the specimen geometries differ. For tests on the aluminum alloy, the gauge length and the thickness are equal to $60 \mathrm{~mm}$ and $3 \mathrm{~mm}$, respectively.

For the same nominal strain rate, the appearance of the PLC effect and in particular, bands of type B occur for various temperatures, $20^{\circ} \mathrm{C}$ and $200{ }^{\circ} \mathrm{C}$, respectively, for aluminum alloy and steel. This result seems to contradict the fact that the diffusion velocity of solute atoms in steel is higher than in aluminum. Thus, the PLC phenomenon should occur for lower temperatures in the case of steel than for aluminum. This observation underlines the importance of other parameters such as the dislocation density and solute atom concentration. In general, these parameters are difficult to estimate

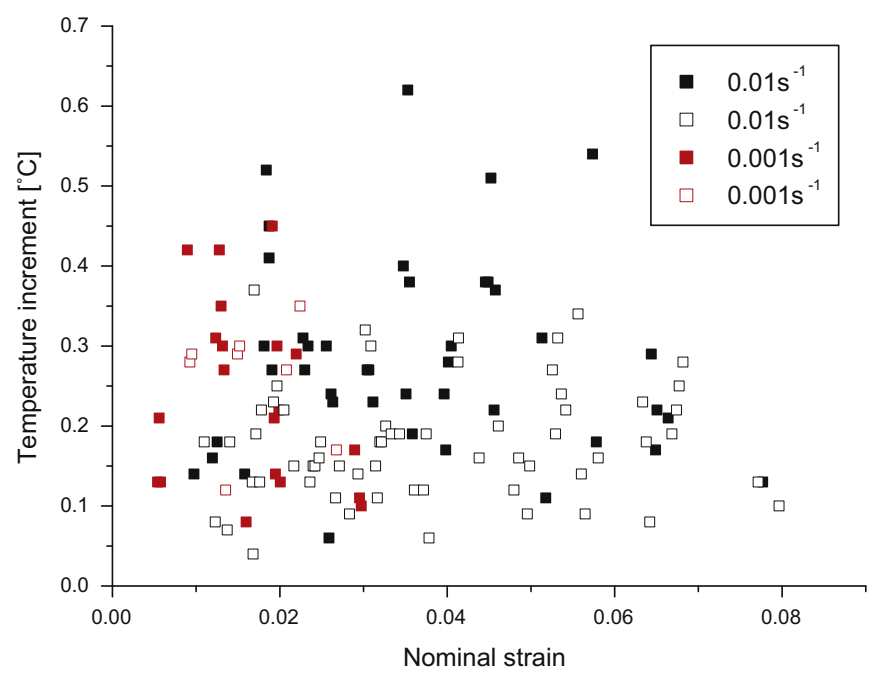

Fig. 13. Temperature increment in bands according to nominal strain for tests 1 and 2 . precisely.

Table 3 summarizes the various band characteristics for the two materials. In general, orders of magnitude of the parameters are the same but some differences exist, in particular between the bandwidth, time between band formations and the increment of plastic strain inside one band. Some of these parameters are interdependent. If it is supposed, for example, that the plastic strain concentrates only in the PLC band and that between two band formations, the plastic strain remains negligible, then the following relationship can be established:

$\Delta \varepsilon=\frac{\dot{\varepsilon} \ell t_{m b}}{d}$

where $d$ is the band width, $\ell$ is the length of the useful part of the specimen, $\dot{\varepsilon}$ is the nominal strain rate and $t_{m b}$ is the time between two band formations. For C-Mn steel, $t_{m b}=23 \mathrm{~ms}$ and a strain increment in one band of $0.67 \%$ is obtained. The same calculation can be made for aluminum, and a strain increment of $1.1 \%$ can be calculated. In both cases, this relationship leads to a slight overestimation of strain increment compared with the experiment. However, the order of magnitude is correct. This overestimation most likely results because the plastic strain is not really equal to zero between two band formations, and during the band formation, a plastic strain always exists outside the band.

The bandwidth is higher for aluminum, but this effect is undoubtedly because of the difference in specimen thickness. Several authors have shown the importance of this effect [15,34]. For example, Shabadi et al. [34] show that for alloy AA7020, an increase in specimen thickness from $1 \mathrm{~mm}$ to $5 \mathrm{~mm}$ creates an increase in bandwidth from $4 \mathrm{~mm}$ to $8.5 \mathrm{~mm}$ at a strain of $5 \%$. For our measurements, the bandwidths remain lower for the two materials but the difference in specimen thickness can explain this bandwidth difference.

\section{Conclusion}

Tensile tests were carried out at $200{ }^{\circ} \mathrm{C}$ on a C-Mn steel. A DSA phenomenon is presented, which leads to the formation of PLC bands. Specimen heating was achieved using an induction furnace. An observation of spatio-temporal organization of these bands and the measurement of their macroscopic characteristics was carried out by infrared thermography. This technique has already been used many times in the literature for test temperatures close to ambient conditions. This study thus shows the possibility of extending this measurement method to higher temperature despite a less favorable signal to noise ratio. Various band parameters were studied such as bandwidth, angle of inclination, distance between two consecutive bands, time between two band formations and apparent band propagation velocity. The increment in plastic strain in the bands was also estimated from the temperature increment in the band using the heat transfer equation. Using this thermography measurement technique, it is also possible to determine the evolution of these parameters according to the nominal plastic strain and nominal strain rate. The presented results were compared with results obtained at ambient

Table 3

Comparison of PLC band characteristics.

\begin{tabular}{|c|c|c|c|c|}
\hline Material & Temperature & Strain $\left[s^{-1}\right]$ & Nominal strain & Bandwidth [mm] \\
\hline $\mathrm{AlCu}_{4} \mathrm{Mg}$ & 20 & $1.19 \times 10^{-2}$ & $15.8 \%$ & 2.9 \\
\hline C-Mn steel & 200 & $10^{-2}$ & $3.5 \%$ & 1.2 \\
\hline Material & $\begin{array}{l}\text { Distance between bands } \\
{[\mathrm{mm}]}\end{array}$ & $\begin{array}{l}\text { Time between two bands } \\
\text { [ms] }\end{array}$ & $\begin{array}{l}\text { Temperature increment } \\
{\left[{ }^{\circ} \mathrm{C}\right]}\end{array}$ & $\begin{array}{l}\text { Plastic strain } \\
\text { increment }\end{array}$ \\
\hline $\mathrm{AlCu}_{4} \mathrm{Mg}$ & 1.4 & 51 & 0.74 & $0.6 \%$ \\
\hline C-Mn Steel & 1.4 & 23 & 0.3 & $0.3 \%$ \\
\hline
\end{tabular}


temperature in an $\mathrm{Al}-\mathrm{Cu}-\mathrm{Mg}$ alloy and using the same experimental technique. This study enables us to conclude the following:

- The thermography measurement technique can be used to observe the PLC phenomenon in steels at $200{ }^{\circ} \mathrm{C}$. It provides good results even if the signal to noise ratio is worse than at ambient temperature.

- For similar test conditions, PLC bands of type B appear at a higher temperature in steel than in aluminum alloy.

- The orders of magnitude of the macroscopic characteristics of the bands are the same as that for C-Mn steel and the aluminum alloy despite different diffusion mechanisms of the solute atoms at microscopic scale.

- Evolution of parameters according to the nominal strain and nominal strain rate appear to be rather similar except for temperature increments in the bands.

\section{Appendix A. Unidimensional model of heat relaxation after one band formation}

To model and estimate the temperature relaxation after PLC band formation, a unidimensional temperature field will be supposed in a parallelepipedic specimen with length $2 \mathrm{~L}$, width $\ell=6 \mathrm{~mm}$ and thickness $e=1.5 \mathrm{~mm}$. On the specimen faces, heat exchange by convection with surroundings at ambient temperature $T_{a}=20^{\circ} \mathrm{C}$ is considered and is modeled by a constant heat convection coefficient $h$, which is assumed equal to $10 \mathrm{~W} \mathrm{~m}^{-2} \mathrm{~K}^{-1}$. Adiabatic boundary conditions are applied on the two ends of the specimen (Fig. 14).

Under these conditions, the heat equation is:

$\frac{\partial \vartheta}{\partial t}=a \frac{\partial^{2} \vartheta}{\partial x^{2}}-\nu \vartheta$

where $a=\frac{k}{\rho C}$ is the thermal diffusivity, $\nu=\frac{h}{\rho C} \frac{2(e+\ell)}{e \ell}$ and $\vartheta=T(x, t)-T_{a}$ represent the temperature variation, and the boundary conditions are:

$\left.\frac{\partial \vartheta}{\partial x}\right|_{x=0}=0$ and $\left.\frac{\partial \vartheta}{\partial x}\right|_{x=L}=0$

The initial temperature condition is $T(x, 0)=f(x)$ where

$f(x)= \begin{cases}T_{1} & \text { if } x \in[0 ; b] \\ T_{1}+\Delta T & \text { if } x \in[b ; L]\end{cases}$

and $T_{1}$ represents the specimen temperature before band formation, $\Delta T$ is the temperature increment after band formation and $b$ is the half width of the band.

A solution of this problem can be found in Ref. [60] on page 144:
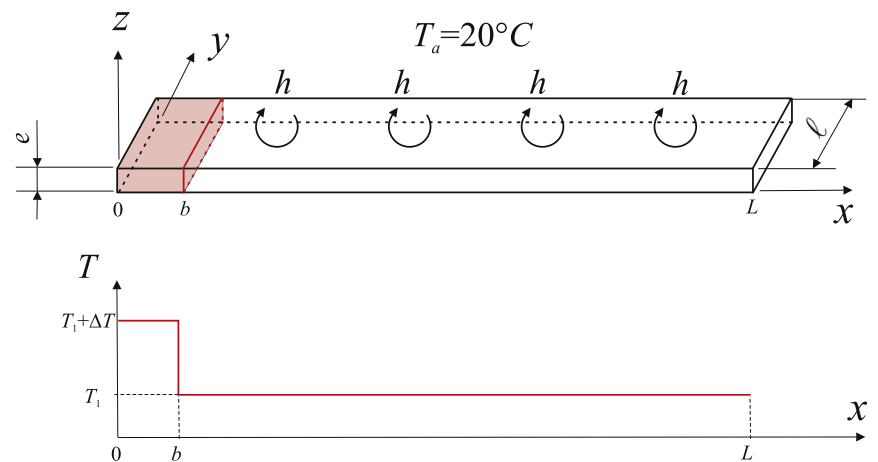

Fig. 14. Thermal model, geometry and initial conditions.

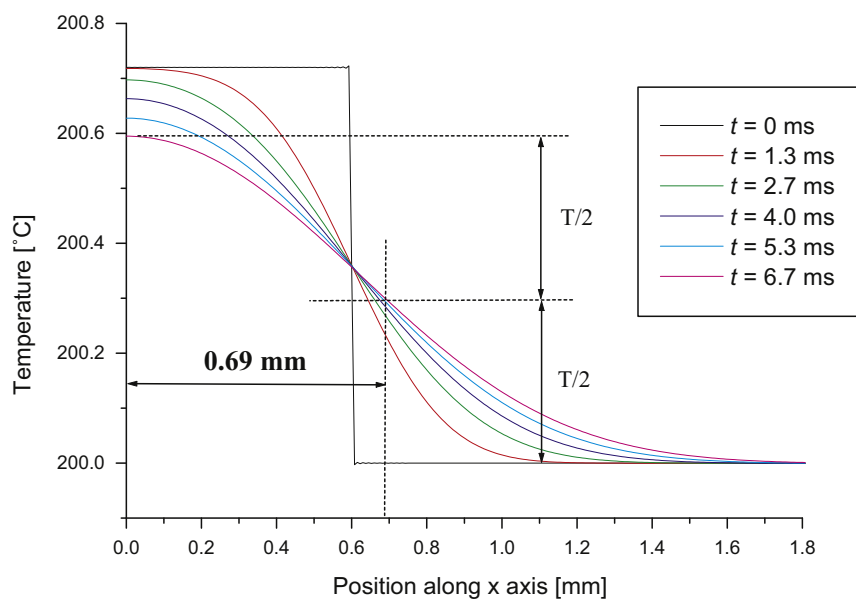

Fig. 15. Thermal model, temperature evolution after a band initiation.

$\vartheta(x, t)$

$$
\begin{aligned}
= & \frac{1}{L} \mathrm{e}^{-\nu t}\left(T_{1} L+b \Delta T\right)+\frac{2}{\pi} \sum_{n=1}^{\infty} \frac{1}{n} \exp \left(-\nu t-\frac{a n^{2} \pi^{2}}{L^{2}}\right) \cos \frac{n \pi x}{L} \\
& \sin \frac{n \pi b}{L}
\end{aligned}
$$

Fig. 15 represents the evolution in temperature profile with time. The last time corresponds to that between two successive images recorded using the camera (e.g., $6.7 \mathrm{~ms}$ ). A decrease in temperature occurs at the center of the band and the hot zone width increases. After $6.7 \mathrm{~ms}$, the temperature variation in the center of the band is approximately $0.13^{\circ} \mathrm{C}$, i.e., a relative error of $17 \%$. In parallel, the width of heat at the middle high temperature is approximately $1.39 \mathrm{~mm}$, which corresponds to a relative error of $16 \%$. The increase in acquisition frequency induces a reduction in these two errors.

\section{References}

[1] J.D. Baird, Strain Ageing of Steel - A Critical Review, Iron and Steel, 36.

[2] A.S. Keh, Y. Nakada, W.C. Leslie, Dynamic Strain Aging, in: A.R. Rosenfield, G. Hahn, New York, 1968, pp. 381-408.

[3] M. Grumbach, G. Sanz, Le vieillissement après écrouissage, Tech. Rep. 5, C.I.T du C.D.S., 1970.

[4] L.J. Cuddy, W.C. Leslie, Some aspects of serrated yielding in substitutional solid solutions of iron, Acta Metall. 20 (10) (1972) 1157-1167.

[5] J.D. Baird, Effects of strain- ageing due to interstitial solutes on the mechanica properties of metals, Met. Rev. (Suppl. Met. Mater.) 16 (149) (1971) 1-18.

[6] J. Baird, Dynamic Strain Aging, ASM International, Metals Park, Ohio, 1973.

[7] F.B. Pickering, Low Carbon Mild Steels, Applied Science Publishers, London, 1978.

[8] P. Bocquet, M. Gutmann, Le Vieillissement, Lavoisier, Paris 1997, pp. 598-613.

[9] D. Wagner, J. Moreno, C. Prioul, Dynamic strain aging sensitivity of heat affected zones in C-Mn steels, J. Nucl. Mater. 252 (3) (1998) 257-265.

[10] D. Wagner, J.C. Moreno, C. Prioul, Dynamic strain ageing in C-Mn steels and associated welds. Effect of metallurgical parameters on the tensile behaviour Rev. Met. Paris 97 (12) (2000) 1481-1500.

[11] H. Neuhäuser, C. Schwink, Solid Solution Strengthening, Wiley-VCH Verlag GmbH \& Co, KGaA, 2006.

[12] B.J. Brindley, P.J. Worthing, Yield point phenomena in substitutional alloys, Met Rev. (Suppl. Met. Mater.) 15 (145) (1970) 101-114.

[13] P. Lacombe, L'effet Portevin Le Chatelier ses caractéristiques et ses conséquences sur les hétérogénéités de déformation plastique, Matériaux et techniques, 1985, E5.

[14] P. Rodriguez, Strain aging dynamic, in: R.W. Cahn (Ed.), Encyclopedia of Materials Science and Engineering, 1, Pergamon, Pergamon, 1988, pp. 504-508.

[15] P. McCormick, S. Venkadesan, C. Ling, Propagative instabilities an experimental view, Scr. Metall. Mater. 29 (9) (1993) 1159-1164.

[16] M. Lebyodkin, L. Dunin-Barkowskii, Y. Bréchet, Y. Estrin, L. Kubin, Spatiotemporal dynamics of the Portevin-Le Chatelier effect experiment and modelling, Acta Mater. 48 (10) (2000) 2529-2541.

[17] P. McCormick, The Portevin-Le Chatelier effect in a pressurized low carbon steel, Acta Metall. 21 (7) (1973) 873-878. 
[18] A. Van den Beukel, Theory of the effect of dynamic strain aging on mechanical properties, Phys. Status Solidi (A) Appl. Res. 30 (1) (1975) 197-206.

[19] H. Neuhäuser, Plastic Instabilities and the Deformation of Metals, Kluwer Academic Publishers 1990, pp. 241-276.

[20] Y. Estrin, L. Kubin, E. Aifantis, Introductory remarks to the viewpoint set on propagative plastic instabilities, Scr. Metall. Mater. 29 (9) (1993) 1147-1150.

[21] Y. Estrin, L. Kubin, Continuum Models for Materials and Microstructure, Wiley, New York, 1995.

[22] W.C. Leslie, Quench and Strain, 5, Pergamon 1986, pp. 4007-4011.

[23] C.W. Marschall, P. Landow, G.M. Wilkowski, Effect of dynamic strain aging on fracture resistance of carbon steels operating at light-water reactor temperatures, ASTM STP 1014 (1990) 339-360.

[24] L. Cheng, N. Van der Pers, A. Bottger, T. de Keijser, E. Mittemeijer, Lattice changes of iron-nitrogen martensite on aging at room temperature, Metall. Trans. A 21 A (11) (1990) 2857-2867.

[25] L. Cheng N. Van der Pers, A. Bötger, T, de Keijser, E. Mittemeijer, Lattice changes of iron-carbon martensite on aging at room temperature, Metall. Trans. A 22 (9) (1991) 1957-1967.

[26] L. Cheng, A. Böttger, E. Mittemeijer, Tempering of iron-carbon-nitrogen martensites, Metall. Trans. A 23 (4) (1992) 1129-1145.

[27] D. Wagner, N. Roubier, C. Prioul, Measurement of sensitivity to dynamic strain aging in C-Mn steels by internal friction experiments, Mater. Sci. Technol. 22 (3) (2006) 301-307.

[28] M. Mazière, J. Besson, S. Forest, B. Tanguy, H. Chalons, F. Vogel, Numerical aspects in the finite element simulation of the Portevin-Le Châtelier effect, Comput. Method. Appl. M. 199 (9-12) (2010) 734-754.

[29] H. Wang, C. Berdin, M. Mazière, S. Forest, C. Prioul, A. Parrot, P. Le-Delliou, Experimental and numerical study of dynamic strain ageing and its relation to ductile fracture of a C-Mn steel, Mater. Sci. Eng. A 547 (2012) 19-31.

[30] A. Ziegenbein, P. Hähner, H. Neuhäuser, Correlation of temporal instabilities and spatial localization during Portevin-Le Châtelier deformation of Cu-10 at\% $\mathrm{Al}$ and Cu-15 at\% Al, Comput. Mater. Sci. 19 (1-4) (2000) 27-34.

[31] F. Klose, A. Ziegenbein, J. Weidenmüller, H. Neuhäuser, P. Hähner, Portevin-Le Châtelier effect in strain and stress controlled tensile tests, Comput. Mater. Sci. 26 (suppl) (2003) 80-86.

[32] L. Casarotto, R. Tutsch, R. Ritter, J. Weidenmüller, A. Ziegenbein, F. Klose, H. Neuhäuser, Propagation of deformation bands investigated by laser scanning extensometry, Comput. Mater. Sci. 26 (Suppl) (2003) 210-218.

[33] L. Casarotto, R. Tutsch, R. Ritter, H. Dierke, F. Klose, H. Neuhäuser, Investigation of PLC bands with optical techniques, Comput. Mater. Sci. 32 (3-4) (2005) 316-322.

[34] R. Shabadi, S. Kumar, H. Roven, E. Dwarakadasa, Characterisation of PLC band parameters using laser speckle technique, Mater. Sci. Eng. A 364 (1-2) (2004) $140-150$.

[35] R. Shabadi, S. Kumar, H. Roven, E. Dwarakadasa, Effect of specimen condition, orientation and alloy composition on PLC band parameters, Mater. Sci. Eng. A 382 (1-2) (2004) 203-208.

[36] Z. Jiang, Q. Zhang, H. Jiang, Z. Chen, X. Wu, Spatial characteristics of the Portevin-Le Châtelier deformation bands in $\mathrm{Al}-4$ at\%Cu polycrystals, Mater. Sci. Eng. A 403 (1-2) (2005) 154-164.

[37] H. Jiang, O. Zhang, X. Wu, J. Fan, Spatiotemporal aspects of the Portevin-Le Chatelier effect in annealed and solution-treated aluminum alloys, Scr. Mater. 54 (12) (2006) 2041-2045.

[38] H. Jiang, Q. Zhang, X. Chen, Z. Chen, Z. Jiang, X. Wu, J. Fan, Three types of Portevin-Le Châtelier effects experiment and modelling, Acta Mater. 55 (7) (2007) 2219-2228.

[39] W. Tong, H. Tao, N. Zhang, L. Hector Jr., Time-resolved strain mapping measurements of individual Portevin-Le Châtelier deformation bands, Scr. Mater. 53 (1) (2005) 87-92.

[40] H. Ait-Amokhtar, P. Vacher, S. Boudrahem, Kinematics fields and spatial activity of Portevin-Le Chatelier bands using the digital image correlation method, Acta Mater. 54 (16) (2006) 4365-4371.

[41] H. Ait-Amokhtar, S. Boudrahem, C. Fressengeas, Spatiotemporal aspects of jerky flow in Al-Mg alloys, in relation with the Mg content, Scr. Mater. 54 (12) (2006) 2113-2118.

[42] H. Halim, D. Wilkinson, M. Niewczas, The Portevin-Le Chatelier (PLC) effect and shear band formation in an AA5754 alloy, Acta Mater. 55 (12) (2007) 4151-4160.

[43] K. Renard, S. Ryelandt, P. Jacques, Characterisation of the Portevin-Le Châtelier effect affecting an austenitic TWIP steel based on digital image correlation, Mater. Sci. Eng. A 527 (12) (2010) 2969-2977.

[44] A. Weck, P. Bisaillon, L. Nong, T. Meunier, H. Jin, M. Gallerneault, Mechanical properties of the aluminum roll-bond laminate AA5005-AA5083-AA5005, Mater. Sci. Eng. A 528 (19-20) (2011) 6186-6193.

[45] N. Ranc, D. Wagner, Some aspects of Portevin-Le Châtelier plastic instabilities investigated by infrared pyrometry, Mater. Sci. Eng. A 394 (1-2) (2005) 87-95.

[46] H. Louche, P. Vacher, R. Arrieux, Thermal observations associated with the Portevin-Le Châtelier effect in an Al-Mg alloy, Mater. Sci. Eng. A 404 (1-2) (2005) 188-196.

[47] N. Ranc, D. Wagner, Experimental study by pyrometry of Portevin-Le Châtelier plastic instabilities - type A to type B transition, Mater. Sci. Eng. A 474 (1-2) (2008) 188-196.

[48] X. Feng, G. Fischer, R. Zielke, B. Svendsen, W. Tillmann, Investigation of PLC band nucleation in AA5754, Mater. Sci. Eng. A 539 (2012) 205-210.

[49] H. Ait-Amokhtar, C. Fressengeas, S. Boudrahem, The dynamics of Portevin-Le Châtelier bands in an Al-Mg alloy from infrared thermography, Mater. Sci. Eng. A 488 (1-2) (2008) 540-546.

[50] A. Benallal, T. Berstad, T. Børvik, O. Hopperstad, R. De Codes, Effects of strain rate on the characteristics of PLC deformation bands for AA5083-H116 aluminium alloy, Philos. Mag. 88 (28-29) (2008) 3311-3338.

[51] H. Ait-Amokhtar, C. Fressengeas, Crossover from continuous to discontinuous propagation in the Portevin-Le Châtelier effect, Acta Mater. 58 (4) (2010) 1342-1349.

[52] R. De Codes, O. Hopperstad, O. Engler, O.-G. Lademo, J. Embury, A. Benallal, Spatial and temporal characteristics of propagating deformation bands in AA5182 alloy at room temperature, Metall. Mater. Trans. A: Phys. Metall. Mater. Sci. 42 (11) (2011) 3358-3369.

[53] S. Lee, J. Kim, S.-J. Lee, B. De Cooman, Effect of nitrogen on the critical strain for dynamic strain aging in high-manganese twinning-induced plasticity steel, Scr. Mater. 65 (6) (2011) 528-531.

[54] Q. Hu, Q. Zhang, P. Cao, S. Fu, Thermal analyses and simulations of the type A and type B Portevin-Le Châtelier effects in an Al-Mg alloy, Acta Mater. 60 (4) (2012) 1647-1657.

[55] R. De Codes, A. Benallal, Influence of specimen geometry on the Portevin-Le Châtelier effect due to dynamic strain aging for the AA5083-H116 aluminum alloy, J. Mech. Mater. Struct. 6 (7-8) (2012) 951-968.

[56] C. Bernard, J. Coër, H. Laurent, P. Chauvelon, P. Manach, Relationship between local strain jumps and temperature bursts due to the Portevin-Le Châtelier effect in an Al-Mg alloy, Exp. Mech. 53 (6) (2013) 1025-1032.

[57] G. Scavino, C. Di Salvo, P. Matteis, R. Sesana, D. Firrao, Portevin-Le Châtelier effects in a high-Mn austenitic steel, Metall. Mater. Trans. A 44 (2) (2013) 787-792.

[58] F. Springer, C. Schwink, On a method to determine directly the waiting time of arrested dislocations and the elementary strain in dynamic strain ageing, Scr. Metall. Mater. 32 (11) (1995) 1771-1776.

[59] J.M. Dorlot, J.P. Baïlon, J. Masouave, Des Matériaux, Ecole Polytechnique de Montréal, Canada, 1986.

[60] H. Carslaw, J. Jaeger, Conduction of Heat in Solids, Oxford science publications, Clarendon Press, 1986. 